http://rev.med.panacea.unica.edu.pe

Rev méd panacea. 2013; 3(2): 59

Recibido: 03 de Agosto del 2013 | Aceptado: 25 de Agosto del 2013 | Publicado: 31 de Agosto del 2013

CONFICTO DE INTERES: NO DECLARADOS

CARTA AL EDITOR

\title{
VIH/SIDA en menores de edad en Perú: situación epidemiológica
}

\section{HIV/AIDS IN CHILDREN OF PERU: EPIDEMIOLOGICAL SITUATION}

\author{
Elleen Cárdenas-Quispe ${ }^{1, a}$, Juan Carlos Flores-Ferreyra ${ }^{1, a}$, Guido Bendezú-Quispe 1,a \\ Sociedad Científica de Estudiantes de Medicina de Ica (SOCEMI) ${ }^{1}$ \\ Estudiante de medicina ${ }^{a}$
}

\section{Sr. Editor.}

$\mathrm{E}$ Programa Conjunto de las Naciones Unidas sobre el VIH/SIDA (ONUSIDA), indicó que durante el período 2009 al 2012, el número de nuevas infecciones por VIH en niños (as) menores de 15 años disminuyó en un 38\%, esto debido a una mayor cobertura en la atención a gestantes VIH (+), lográndose que cuatro de cada diez embarazadas recibieron medicamentos antirretrovirales para prevenir la transmisión vertical y que cinco de cada diez madres o sus hijos recibieron tratamiento antirretroviral durante la lactancia. Además durante el año 2012, el número de niños menores de 15 años que vivían con el VIH era de 3,3 millones, un aproximado de 260 mil de nuevas infecciones en el mismo grupo etario y 210 mil muertes a causa del SIDA, además de una disminución del 52\% de nuevas infecciones en niños respecto al año anterior (1).

Según UNICEF desde el año 2011 más de 17 millones de niños quedaron huérfanos de uno o ambos padres a causa del SIDA. Los niños huérfanos a causa del VIH y de bajo nivel socioeconómico son muy vulnerables pues sufren pérdida del hogar, falta de oportunidades para su desarrollo, rechazo y discriminación de la sociedad, además de una muerte prematura (2). El 90\% de menores que padecen SIDA y no han sido detectados mueren antes de los 5 años porque no han tenido acceso al tratamiento antirretroviral y/o por otras enfermedades como neumonía o diarreas (3)

En Perú, durante el año 2004 se emitió la ley $N^{\circ} 28243$ que promulga y ordena un tamizaje obligatorio a toda madre gestante previa consejería, con la finalidad de proteger la salud del niño por nacer y mantener con vida a su madre. En el año 2011 esta cobertura llegó al 79.6\% de gestantes, con algunas desventajas debido al desabastecimiento de reactivos (4). En el Informe Nacional sobre los Progresos Realizados en el Perú de la ONUSIDA, presentado en el 2012, indicó que se atendió al $91.67 \%$ de gestantes VIH seropositivas y sus niños expuestos pudieron acceder a un tratamiento preventivo de la transmisión vertical en comparación con el del 2004 que se atendió 47.5\% de gestantes VIH seropositivas (5).

Con respecto a los casos acumulados desde 1983 hasta el 2013, en la región Ica se notificaron 19 casos en menores de 4 años, 5 casos en el grupo de 5 a 9 años. La vía principal de infección de VIH/SIDA en la región Ica es la forma sexual, habiéndose registrado hasta septiembre del 2013, un total de 29 infectados (2,33\%) por vía vertical (6).

Se aprecia una disminución a más de la mitad en el número de infecciones de VIH en menores a nivel mundial, debido al incremento en los esfuerzos por cubrir las necesidades del tratamiento antirretroviral en gestante, durante el intraparto como en el postparto. Sin embargo, estas cifras han de disminuir por un tema de oportunidades y bienestar para los menores que podrían verse afectados por un no control de riesgos en la transmisión. Las metas regionales y nacionales deben orientarse a llevar al mínimo el número de casos nuevos infectados en menores de edad, para promover y asegurar su desarrollo integral, su autonomía y construcción como sujetos sociales y titulares de sus derechos.

\section{REFERENCIAS BIBLIOGRÁFICAS}

1. Programa Conjunto de las Naciones Unidas sobre el VIH/SIDA (ONUSIDA). Informe de ONUSIDA sobre la epidemia mundial de SIDA, 2013 [acceso 27 de Abril del 2013]. Disponible en: http://www.unaids.org/en/ media/unaids/contentassets/documents/ epidemiology/2013/gr2013/

UNAIDS_Global_Report_2013_en.pdf

2. United Nations Children's Fund (UNICEF)

[sede web].2013.Protección, cuidado y apoyo a los niños afectados por el VIH y SIDA. [Actualizado 13 de Marzo del 2013: acceso 27 de Abril del 2013]. Disponible en: http://www.unicef.org/aids/ index_armedconflict.html

3. United Nations Children's Fund (UNICEF). Unidos por la infancia 1946 - 2006.Lima; 200

4. Dirección general de Epidemiología. Ministerio de Salud del Perú. Boletín epidemiológico 2013; №39:819 -821. 2013 [acceso 29 de abril del 2013].Disponible en: www.dge.gob.pe/boletin.php

5. Programa conjunto de las Naciones Unidas sobre el VIH/SIDA (ONUSIDA). Informe Nacional sobre los Progresos Realizados en el Perú. [Sede Web].Perú; 2012.

6. Dirección Regional de Salud Ica (DIRESA). Ministerio de Salud del Perú. Boletín epidemiológico Mensual septiembre 2013.

\section{CITA SUGERIDA.}

Cárdenas-Quispe E, Flores-Ferreyra JC, Bendezú -Quispe G. VIH/SIDA en menores de edad en Perú: situación epidemiológica. Rev méd panacea.2013; 3 (2):59 